\title{
ESTUDOS DO COMPORTAMENTO DE MISTURA DE MINÉRIO DE FERRO NO PROCESSO DE MOAGEM DE PELOTIZAÇÃO*
}

\section{Resumo}

Catia Casagrande ${ }^{1}$

Tatiane Alvarenga ${ }^{2}$

Lumena Nunes 3

As principais operações unitárias de um processo de pelotização são: moagem, filtragem, aglomeração e queima. Das etapas citadas, a moagem, como início do processo, é uma etapa crucial para as demais operações. Foi baseado neste fato, que o presente estudo foi realizado, tendo como objetivo principal, avaliar o comportamento das misturas de minério de ferro com diferentes índices de moabilidade e definir os possíveis ajustes dos parâmetros de processo de moagem em função dos diferentes perfis mineralógicos. Foram usadas três misturas de diferentes níveis de índices de moabilidade: baixo, médio e alto, a fim de observar as respostas nas variáveis operacionais de possível atuação na rotina operacional. Para isso, uma matriz de experimento foi realizada, com oito testes para cada mistura de minério de ferro, variando os parâmetros de moagem de mínimo a máximo. As variáveis respostas foram às características físicas das misturas, superfície específica e granulometria, onde foram medidas no sistema automatizado PSI. Através dos resultados dos testes, foram calculados modelos matemáticos de superfície específica e granulometria das misturas em função dos parâmetros operacionais. Os modelos mostraram satisfatórios e aplicáveis, apresentando correlação entre as variáveis dependentes e independentes.

Palavras-chave: Índice de moabilidade; Minério de ferro; Granulometria; Superfície específica.

\section{STUDIES OF THE BEHAVIOR OF IRON ORE MIXTURE IN THE GRINDING PELLETIZING PROCESS}

\begin{abstract}
The main unit operations of a pelletizing process are: grinding, filtering, clustering and fired. Of the steps mentioned, the griding, as first of the process, is a crucial step for the other operations. It was based on this fact, that the present study was performed, having as its main objective, to evaluate the behavior of iron ore mixtures with different grindability indexes and define the possible adjustment of process parameters of grinding against the different mineralogical profiles. Three different mixtures of grindability indexes were used: low, medium and high, in order to observe the responses in the operational variables that it is possible performance in operating routine. For this, an experiment matrix was performed, with eight tests over each iron ore mixture, by varying the minimum and maximum grinding parameters. Independent variables were the physical characteristics of the mixtures, specific surface and particle size, where they were measured in the automated system PSI. Through the results of the tests, mathematical models have been estimated specific surface and particle size of mixtures as a function of the operating parameters. The models the models showed applicable and satisfactory and the models showed applicable and satisfactory, and correlation between dependent and independent variables.

Keywords: Grindability index; Iron ore; Particle size; Specific surface.

1 Engenharia Geológica, Mestre em Engenharia de Materiais, Engenheira, Diretoria de Pelotização, Vale, Vitória, ES, Brasil.

2 Técnico de Metalurgia, Técnica Especialista, Diretoria de Pelotização, Vale, Vitória, ES, Brasil.

3 Engenharia Metalúrgica, Engenheira, Diretoria de Pelotização, Vale, Vitória, ES, Brasil.
\end{abstract}

* Contribuição técnica ao $44^{\circ}$ Seminário de Redução de Minério de Ferro e Matérias-primas, 15o Simpósio Brasileiro de Minério de Ferro e 2o Simpósio Brasileiro de Aglomeração de Minério de Ferro, 15 a 18 de setembro de 2014, Belo Horizonte, MG, Brasil. 


\section{INTRODUÇÃO}

Os minérios de ferro possuem características físicas, químicas e mineralógicas que necessitam de adequações em seu tratamento para alimentar processos subsequentes como concentração e pelotização. No processo de pelotização, as operações unitárias mais importantes são moagem, filtragem, prensagem, aglomeração/pelotização e queima.

A moagem pode ser considerada uma etapa fundamental, pois adequa as características físicas do minério de ferro nas especificações do pelotamento. Os moinhos são equipamentos de alto custo e seu correto dimensionamento consiste, principalmente, em determinar a quantidade de energia que os minérios vão demandar para atingir um determinado tamanho.

Para prever o comportamento da moagem em função do minério de ferro, tornou-se necessário estabelecer um indicador. Foi desenvolvido e criado na pelotização da Vale, no início dos anos oitenta, um índice correlacionável com a superfície especifica gerada, após a cominuição em moinhos de bolas em circuito fechado. Este foi denominado no processo como índice de moabilidade. Este foi um grande avanço na etapa de predição de comportamento mineralógico na Vale. Logo após, foram classificados os principais produtos das minas destinados à pelotização e esse critério passou a ser utilizado para formação das pilhas de minério, segundo Ribeiro [1].

A moagem, sendo a primeira etapa no processo de pelotização, naturalmente define a eficiência dos processos sequentes. As especificações físicas do processo do produto final de moagem é a superfície específica e granulometria, estas variáveis são de suma importância no processo de pelotização.

Segundo Schneider [2], na produção de pellet feed, uma variável de controle importante é a superfície específica média da população de partículas do minério de ferro concentrado. Quanto maior a superfície específica média, maior a área superficial da população de partículas, favorecendo o processo de pelotização, independendo do método. Por outro lado, superfície específica é gerada pela cominuição do concentrado do minério de ferro, processo que impacta expressivamente o custo de produção de pellet feed moído.

Outro controle é o da granulometria do pellet feed que influência no processo de moagem e aglomeração. A pelotização da Vale controla a percentagem abaixo de $0,045 \mathrm{~mm}$ nas usinas de pelotização. Quanto maior a percentagem nesta fração, maior a eficiência da aglomeração dos finos de minérios de ferro.

A eficiência de quebra das partículas de minério de ferro no interior do moinho pode ser diferente de acordo com a gênese das minas, influência do manto de intemperismo e espessura do mesmo relacionado a cada litologia, zonas de falhas e fraturas. Ao longo dos anos de exploração de uma mina, as características dos minérios de ferro se alteram. O término de vida útil da mesma, a profundidade da cava, a exploração de novas frentes de lavra, entre outros fatores interferem no processo padrão da usina de pelotização, consequentemente na eficiência de cominuição.

Por estes motivos, se fez necessário um estudo para ajustar o processo de moagem com diferentes índices de moabilidade da mistura de minério de ferro.

O estudo teve como objetivo avaliar o comportamento das misturas de minério de ferro com diferentes índices de moabilidade, alterando três parâmetros de processo de moagem. As três misturas de minério de ferro foram selecionadas de acordo com

\footnotetext{
* Contribuição técnica ao 44 Seminário de Redução de Minério de Ferro e Matérias-primas, $15^{\circ}$ Simpósio Brasileiro de Minério de Ferro e $2^{\circ}$ Simpósio Brasileiro de Aglomeração de Minério de Ferro, 15 a 18 de setembro de 2014, Belo Horizonte, MG, Brasil.
} 
os índices de moabilidade, baixo, médio e alto, a fim de observar as respostas operacionais.

\section{MATERIAIS E MÉTODOS}

\subsection{Seleções de Parâmetros}

Para realização dos testes foram selecionados os parâmetros de possível atuação na rotina operacional do operador de área:

- Taxa de alimentação

- Densidade

- Pressão de hidroclone

Estes parâmetros foram padronizados testando em campo os valores máximos e mínimos que seriam utilizados no trabalho.

\subsection{Composições de Misturas e Testes Laboratoriais}

As misturas de minério de ferro utilizadas para o estudo foram compostas por minérios dos Complexos de Mariana, Minas Centrais e Itabira. Foram formadas três misturas com índices de diferentes moabilidade, atendendo as especificações químicas e físicas do processo industrial.

As misturas de minérios de ferro que alimentaram a usina de pelotização, são compostas por 12 lotes, que por sua vez, possui aproximadamente à 6000ton. As amostras foram coletadas a cada $4 \mathrm{~h}$ ao longo de cada pilha na entrada do moinho, em amostrador manual no chute de alimentação, realizando cortes em três partes, laterais e centro. Os incrementos foram homogeneizados originando uma amostra global para caracterização física, química e mineralógica.

Quanto à definição dos três níveis de índice de moabilididade, a gerência de Controle de Produção, elabora a composição da mistura. Baseado nas informações de caracterização química, física e índice de moabilidade do minério de ferro enviadas pelas minas. $O$ índice de moabilidade desta mistura é calculado por média ponderada.

Assim, foram selecionados três índices de moabilidade da mistura, baixo, médio e alto, sendo eles, $1.44,1.68$ e $2.00 \mathrm{~cm}^{2} / \mathrm{gWh}$, respectivamente, com intuito de avaliar o comportamento destas misturas no processo de moagem. De acordo com estes índices de moabilidade, as pilhas foram classificadas como dura, referência e macia. A pilha referência foi nomeada por apresentar o índice de moabilidade próximo do padrão que é utilizada na usina industrial.

Para atender o índice de moabilidade desejado, foi necessário selecionar diversos minérios de ferro com índices de moabilidade distintos. A tabela 1 apresenta as pilhas com participação de complexos devido à flexibilidade de minérios de ferro.

Tabela 1. Participações dos minérios de ferro nas pilhas classificadas como macia, referência e dura.

\begin{tabular}{cccc}
\hline Complexos & $\begin{array}{c}\text { Pilha } \\
\text { Dura }\end{array}$ & $\begin{array}{c}\text { Pilha } \\
\text { Referência }\end{array}$ & $\begin{array}{c}\text { Pilha } \\
\text { Macia }\end{array}$ \\
\hline Itabira & $73,2 \%$ & $52,3 \%$ & $43,6 \%$ \\
\hline Minas Centrais & $26,8 \%$ & $32,4 \%$ & $9,1 \%$ \\
\hline Mariana & $0 \%$ & $15,3 \%$ & $47,3 \%$ \\
\hline
\end{tabular}

* Contribuição técnica ao 44 Seminário de Redução de Minério de Ferro e Matérias-primas, $15^{\circ}$ Simpósio Brasileiro de Minério de Ferro e 2o Simpósio Brasileiro de Aglomeração de Minério de Ferro, 15 a 18 de setembro de 2014, Belo Horizonte, MG, Brasil. 


\subsection{Testes Laboratoriais}

Os minérios individuais foram submetidos à caracterização completa, isto é, química, física e mineralógica. A análise mineralógica foi realizada através de microscopia ótica. A caracterização dos minérios e misturas foi realizada nos laboratórios da Diretoria de Petolização em Tubarão/Vitória, exceto as análises em microscopia ótica que foram realizadas na Fundação Gorceix/UFOP. Para realizar análise química foi utilizada espectroscopia de fluorescência de raios- $X$ da Rigaku.

A previsibilidade do comportamento da moagem das plantas de pelotização dos diferentes minérios de ferro foi analisada quanto a sua resistência a moagem, através de um ensaio de bancada, desenvolvido com base na Lei de Rittinguer segundo Mourão [3].

Para o ensaio de moabilidade foi construído um moinho cilíndrico ligado a um motor redutor, cuja energia é medida ao final do ensaio. O nível de enchimento, a velocidade, o tempo de duração e a porcentagem de sólidos são fixados. A superfície específica do minério é medida antes e após a moagem. O índice de moabilidade é o resultado da divisão da superfície específica gerada pela energia consumida e é expresso na unidade $\mathrm{cm}^{2} /(\mathrm{gWh})$.

\subsection{Tratamento Estatístico}

O tratamento estatístico se dividiu em três etapas:

1. Preparação do DOE;

2. Tratamento de dados e analise estatística;

3. Obtenção de equações.

\subsubsection{Preparação do DOE}

O planejamento fatorial é uma técnica bastante utilizada quando se tem duas ou mais variáveis independentes (fatores). Ele permite uma combinação de todas as variáveis em todos os níveis, obtendo-se assim uma análise de uma variável, sujeita a todas as combinações das demais.

Planejamentos fatoriais são extremamente úteis para medir os efeitos (ou influências) de uma ou mais variáveis na resposta de um processo. O usual é realizar um planejamento com dois níveis, no máximo três. O uso de mais níveis aumentaria sobremaneira o número de pontos experimentais, fato este que se quer evitar quando se propõe um planejamento.

O planejamento fatorial é a única maneira de prever interação entre os fatores. No presente estudo foi realizado um planejamento fatorial em dois níveis $2 \mathrm{k}^{2}$. Todo o planejamento foi feito com auxilio do software Minitab.

Após preparação no Minitab, foram definidos oito testes ao longo de cada mistura de minério de ferro, variando os parâmetros de moagem tais como, taxa de produção, densidade da descarga e pressão de bomba de mínimo a máximo, (Tabela 2). As variáveis independentes foram às características físicas das misturas, superfície específica e granulometria, onde foram observadas no sistema automatizado PSI.

Tabela 2. Parâmetros de controle de moagem de mínimo a máximo.

\begin{tabular}{ccc}
\hline Parâmetros de controle & Mínimo & Máximo \\
\hline Taxa de produção $(\mathrm{t} / \mathrm{h})$ & 225 & 310 \\
\hline Densidade da descarga $\left(\mathrm{g} / \mathrm{cm}^{2}\right)$ & 2,50 & 3,05 \\
\hline Pressão de bomba $(\mathrm{kgf} / \mathrm{cm})$ & 0,75 & 1,25 \\
\hline
\end{tabular}

* Contribuição técnica ao 44 Seminário de Redução de Minério de Ferro e Matérias-primas, $15^{\circ}$ Simpósio Brasileiro de Minério de Ferro e $2^{\circ}$ Simpósio Brasileiro de Aglomeração de Minério de Ferro, 15 a 18 de setembro de 2014, Belo Horizonte, MG, Brasil. 
Como sugere a teoria os parâmetros do processo de moagem escolhidos foram aleatorizados.

Tabela 3. Testes alegorizando os parâmetros do processo de moagem.

\begin{tabular}{cccc}
\hline Testes & $\begin{array}{c}\text { Taxa de Produção } \\
(\mathrm{t} / \mathrm{h})\end{array}$ & $\begin{array}{c}\text { Densidade da } \\
\text { descarga }\left(\mathrm{g} / \mathrm{cm}^{2}\right)\end{array}$ & $\begin{array}{c}\text { Pressão de } \\
\text { bomba }\left(\mathrm{kgf} / \mathrm{cm}^{2}\right)\end{array}$ \\
\hline 1 & 225 & 3,05 & 0,75 \\
\hline 2 & 310 & 2,50 & 0,75 \\
\hline 3 & 225 & 3,05 & 1,25 \\
\hline 4 & 225 & 2,50 & 1,25 \\
\hline 5 & 310 & 3,05 & 1,25 \\
\hline 6 & 225 & 2,50 & 0,75 \\
\hline 7 & 310 & 3,05 & 0,75 \\
\hline 8 & 310 & 2,50 & 1,25 \\
\hline
\end{tabular}

\subsubsection{Tratamento de dados}

Foi padronizado um período de $4 \mathrm{~h}$ em que um moinho selecionado ficaria de operação com os parâmetros definidos no processo anterior. Após as $4 \mathrm{~h}$, se verificado a estabilização da planta através de amostragem de circuito, os dados de processo foram registrados.

A coleta da densidade da polpa foi feita manualmente na descarga do moinho em caneco de 1I, pesado em balança digital.

As fontes de dados foram o sistema PIMS e PSI500, responsáveis pelos dados de processo e qualidade respectivamente. O fator densidade da polpa na descarga do moinho foi coletado e medido no local por falta de automatismo deste sistema.

A próxima etapa foi o filtro dos dados e eliminação de qualquer instabilidade.

Através do Minitab foi realizado o tratamento estatístico, obtendo-se, assim as relações de interação dos fatores.

\subsubsection{Obtenção de equações}

Foram gerados, através de regressão multi-variável, modelos matemáticos de superfície específica e granulometria em função da taxa de produção, densidade da descarga e pressão de bomba. No período do teste da pilha dura, houve indisponibilidade do sistema automatizado PIS, impactando no monitoramento e levantamento dos resultados de superfície específica e granulometria. Para mitigar a ausência do PSI foi feito coleta manual do circuito dos hidrociclones e analisado via laboratório. Porém como foram coletadas as amostras pontuais, os dados não ficaram coerentes.

\section{RESULTADOS E DISCUSSÃO}

A tabela 4 apresenta os resultados de análise química das pilhas dura, referência e macia.

Tabela 4. Resultados de análise química das pilhas dura, referência e macia.

\begin{tabular}{cccc}
\hline Parâmetros & Pilha Dura & Pilha Referência & Pilha Macia \\
\hline $\mathrm{Fe}_{2} \mathrm{O}_{3}(\%)$ & 67,42 & 66,90 & 66,54 \\
\hline $\mathrm{SiO}_{2}(\%)$ & 2,12 & 2,14 & 2,20 \\
\hline $\mathrm{Al}_{2} \mathrm{O}_{3}(\%)$ & 0,24 & 0,31 & 0,29 \\
\hline $\mathrm{P}(\%)$ & 0,014 & 0,023 & 0,032 \\
\hline $\mathrm{Mn}(\%)$ & 0,05 & 0,06 & 0,09 \\
\hline $\mathrm{CaO}(\%)$ & 0,41 & 0,57 & 0,58 \\
\hline
\end{tabular}

* Contribuição técnica ao $44^{\circ}$ Seminário de Redução de Minério de Ferro e Matérias-primas, 15은 Simpósio Brasileiro de Minério de Ferro e $2^{\circ}$ Simpósio Brasileiro de Aglomeração de Minério de Ferro, 15 a 18 de setembro de 2014, Belo Horizonte, MG, Brasil. 


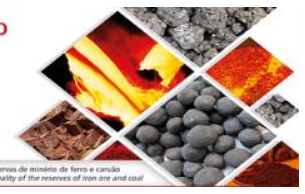

Nota-se que os resultados de química não diferem um dos outros, devido atender a especificação do processo de pelotização. Como sendo um estudo realizado em planta industrial, não foi possível alterar a característica química especificada. A tabela 5 mostra os resultados de análise física das pilhas dura, referência e macia.

Tabela 5. Resultados da análise de física das pilhas dura, referência e macia.

\begin{tabular}{cccc}
\hline Análises físicas & Pilha Dura & Pilha Referência & Pilha Macia \\
\hline$\%<0,045 \mathrm{~mm}$ & 36,63 & 36,36 & 42,61 \\
\hline Índice de Moabilidade $\left(\mathrm{cm}^{2} / \mathrm{gWh}\right)$ & 1,44 & 1,68 & 2,00 \\
\hline
\end{tabular}

A pilha macia apresenta maior participação na faixa abaixo de $0,045 \mathrm{~mm}$, como pode ser visto na tabela 5 . Sendo considerada a mistura mais fina, além do índice de moabilidade maior. A energia para moer a mistura da pilha macia para atingir a especificação granulométrica é menor do que as demais pilhas.

A tabela 6 apresenta os resultados completos de microscopia ótica das pilhas, onde foram identificados os minerais e a microestrutura dos mesmos.

Tabela 6. Resultados de microscopia ótica das pilhas dura, referência e macia.

\begin{tabular}{cccc}
\hline Minerais & $\begin{array}{c}\text { Pilha } \\
\text { Dura }\end{array}$ & $\begin{array}{c}\text { Pilha } \\
\text { Referência }\end{array}$ & $\begin{array}{c}\text { Pilha } \\
\text { Macia }\end{array}$ \\
\hline Hematita tabular monocristalina (\%) & 34,90 & 38,88 & 39,91 \\
\hline Hematita granular monocristalina (\%) & 46,38 & 42,59 & 26,76 \\
\hline Hematita tabular policristalina (\%) & 1,83 & 1,60 & 0,36 \\
\hline Hematita granular policristalina (\%) & 1,96 & 1,24 & 0,07 \\
\hline Hematita lobular (\%) & 2,24 & 3,47 & 4,00 \\
\hline Martita (\%) & 4,17 & 4,83 & 12,97 \\
\hline Magnetita (\%) & 1,16 & 1,00 & 5,25 \\
\hline Goethita (\%) & 1,17 & 4,03 & 7,67 \\
\hline Quartzo + Outros (\%) & 1,84 & 0,87 & 1,78 \\
\hline
\end{tabular}

Em relação aos resultados de microscopia ótica, a pilha macia apresenta maior quantidade de minerais porosos (martita e goethita) que as demais pilhas. Como também a participação de magnetita desta pilha é maior do que as dura e referência. A figura 1 apresenta os resultados de hematita tabular e granular das pilhas dura, referência e macia.

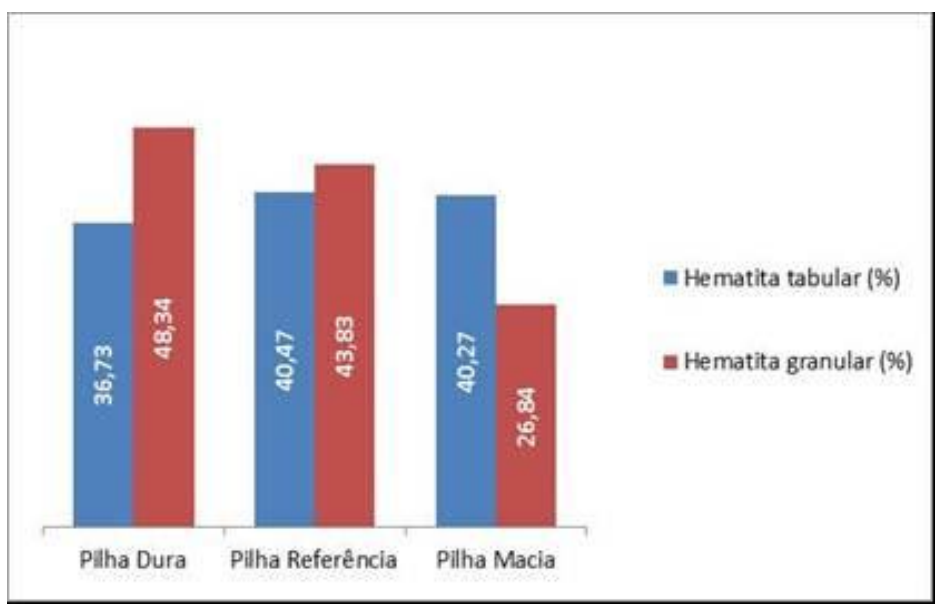

Figura 1. Gráfico dos resultados de hematita tabular e granular das pilhas.

* Contribuição técnica ao 44 Seminário de Redução de Minério de Ferro e Matérias-primas, 15o Simpósio Brasileiro de Minério de Ferro e 2o Simpósio Brasileiro de Aglomeração de Minério de Ferro, 15 a 18 de setembro de 2014, Belo Horizonte, MG, Brasil. 
O gráfico mostra que a pilha dura com índice de moabilidade baixa apresenta maior quantidade de hematita granular do que tabular. Enquanto que a pilha macia à relação granular/tabular é ao contrário. Sabe-se que partículas de microestrutura granular consome maior energia para cominuir do que tabular.

A figura 2 mostra os resultados de participação de minerais porosos das pilhas dura, referência e macia, que possuem índice de moabilidade de 1.44, 1.68 e 2,00 $\mathrm{cm}^{2} / \mathrm{gWh}$, respectivamente.

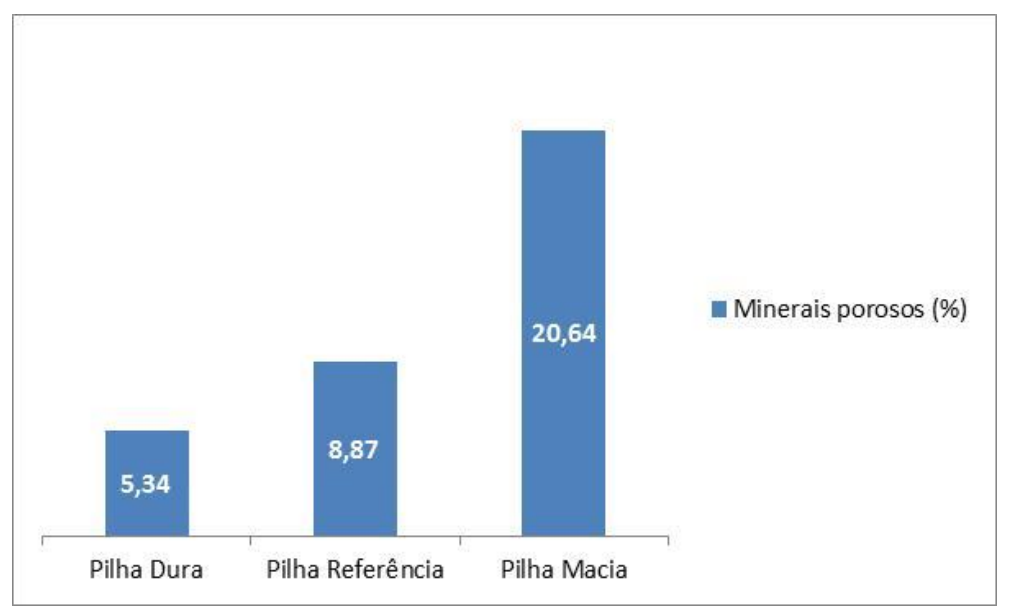

Figura 2. Gráfico dos resultados de participação de minérios porosos das pilhas.

A participação de minerais porosos na pilha macia é quatro vezes maior que na pilha dura, como pode ser vista na Figura 2.

Quanto maior o índice de moabilidade, maior a participação de minerais porosos.

Conforme descrito no item anterior, não foi possível obter os dados de superfície específica e granulometria da pilha dura devido à indisponibilidade do sistema automatizado PSI.

A figura 3 apresenta o gráfico de pareto (a) e os efeitos opostos da produção e densidade da polpa na descarga do moinho em relação à superfície específica (b) da pilha referência.
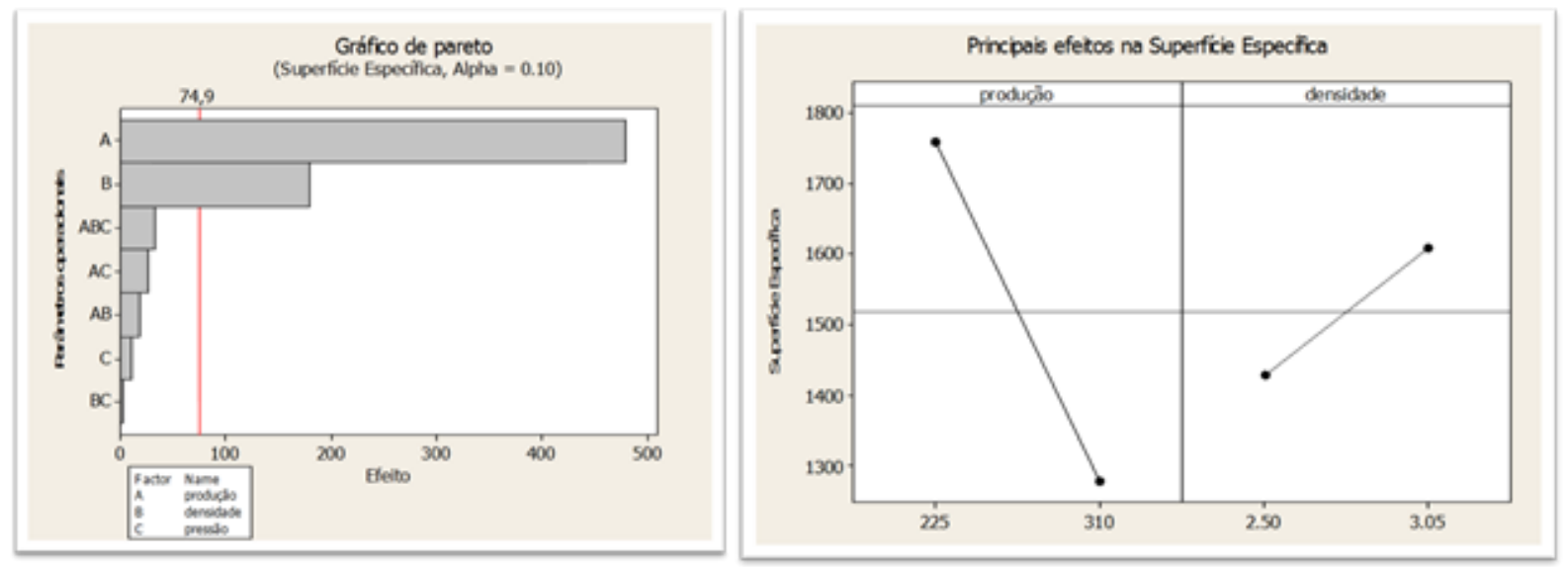

Figura 3. (a) Gráficos de pareto evidenciando o efeito da produção e densidade e (b) Efeitos opostos da produção e densidade em relação à superfície específica da pilha referência.

No gráfico de pareto foi verificado que os parâmetros operacionais, produção e densidade, possuem efeitos na superfície específica. No gráfico na Figura 3(b), podemos evidenciar que a taxa de produção é inversamente proporcional a

* Contribuição técnica ao 44 Seminário de Redução de Minério de Ferro e Matérias-primas, 15은 Simpósio Brasileiro de Minério de Ferro e $2^{\circ}$ Simpósio Brasileiro de Aglomeração de Minério de Ferro, 15 a 18 de setembro de 2014, Belo Horizonte, MG, Brasil. 
superfície específica. Enquanto que a densidade tem relação direta com a superfície específica. Porém sabemos que esta variável (densidade) possui um limite máximo, onde seu efeito se inverte. Este limite não foi medido durante o teste.

A figura 4 mostra o gráfico de pareto (a) e os efeitos opostos da produção e densidade da polpa na descarga do moinho em relação à granulometria (b) da pilha referência.
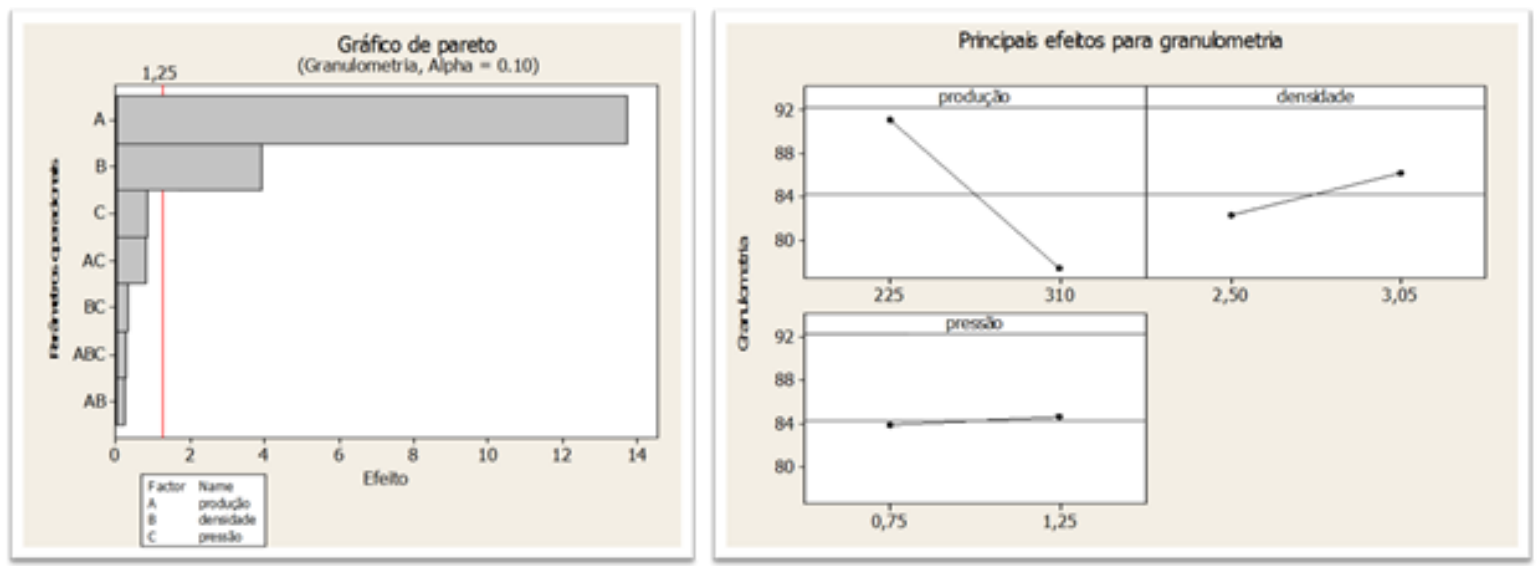

Figura 4. (a) Gráficos de pareto evidenciando o efeito da produção e densidade e (b) Efeitos opostos da produção e densidade em relação à granulometria da pilha referência.

Os parâmetros operacionais como produção e densidade possuem efeito na superfície específica. Em relação aos principais efeitos para granulometria, a produção é inversamente proporcional a granulometria, enquanto que a densidade é ao contrário. A pressão é diretamente proporcional a granulometria, porém seu efeito é menor.

A figura 5 apresenta o gráfico de pareto (a) e os principais efeitos da superfície específica (b) da pilha macia.
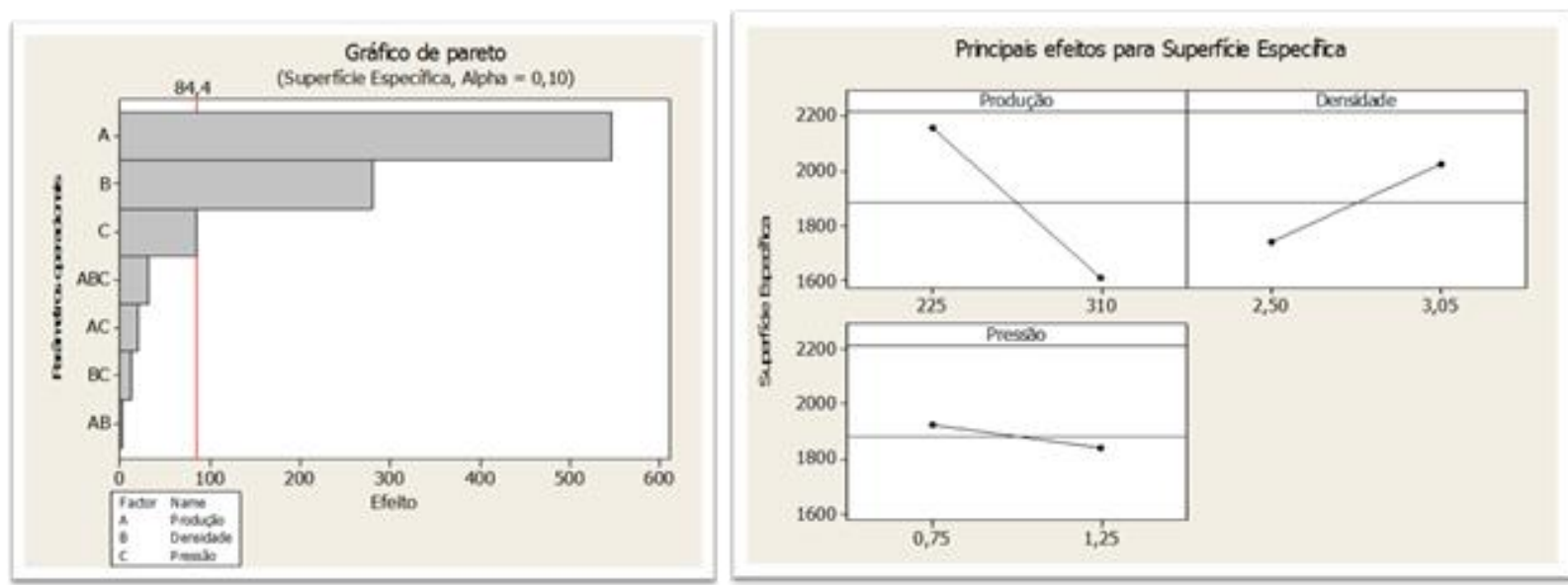

Figura 5. (a) Gráfico de pareto evidenciando o efeito da produção e densidade e (b) Efeitos opostos da produção e densidade em relação à superfície específica da pilha macia.

Foi verificado que os parâmetros, produção, pressão e densidade possuem efeito na superfície específica. Em relação aos efeitos, a taxa de produção é inversamente proporcional a granulometria, enquanto que a pressão apresenta efeito menor, porém apresenta tendência inversamente proporcional a granulometria. Em relação à densidade, existe uma relação direta entre a densidade da descarga e granulometria. 
A figura 6 apresenta o gráfico de pareto (a) e os principais efeitos em relação à granulometria (b) da pilha macia.
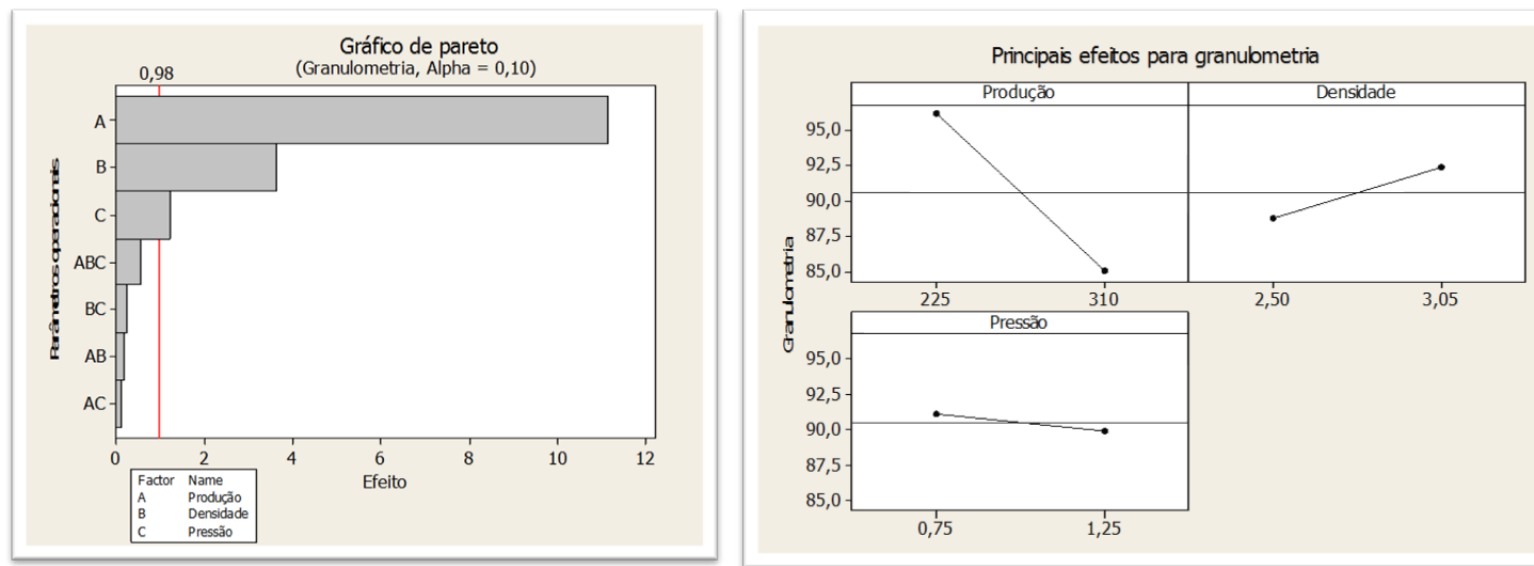

Figura 6: (a) Gráfico de pareto evidenciando o efeito da produção e densidade e (b) Principais efeitos em relação à granulometria da pilha macia.

Através dos resultados e o tratamento estatístico foi possível obter modelos matemáticos para prever a superfície específica e granulometria, como também os parâmetros operacionais de moagem. A Figura 6 mostra a previsibilidade da granulometria da pilha referência em função da taxa de produção, densidade e pressão de bomba. Isto também foi possível obter para superfície específica em um mesmo tipo de pilha e ambos para pilha macia.

Os modelos matemáticos obtidos através deste estudo foram para as pilhas referência e dura, sendo um cálculo de previsibilidade para superfície específica e outro para granulometria. O cálculo de previsibilidade da superfície específica (SE) para pilha referência esta descrito na equação 1, e da granulometria (Gran) para mesma pilha pode ser observado na equação 2.

$$
\begin{gathered}
\text { SE }=2141,29-5,64 \text { * produção }+327,47 \text { * densidade }-21,88 \text { * pressão (1) } \\
\text { Gran }=106,32-0,16 \text { * produção }+7,07 \text { * densidade }+1,65 \text { * pressão (2) }
\end{gathered}
$$

Enquanto que os cálculos de previsibilidade da superfície específica e granulometria da pilha macia estão descritos nos cálculos 3 e 4, respectivamente.

$$
\begin{gathered}
\text { SE }=2352,93-6,43 \text { * produção }+511,33 \text { * densidade }-170,10 \text { * pressão (3) } \\
\text { Gran }=109,84-0,13 \text { * produção }+6,58 \text { * densidade }+2,44 \text { * pressão (4) }
\end{gathered}
$$

Em relação ao índice de correlação, todos os modelos apresentaram valores acima de $98 \%$.

\section{CONCLUSÃO}

O presente estudo mostrou-se satisfatório para determinação da influencia mineralógica na etapa de moagem. Os resultados mostraram que a participação de minerais porosos e relação de hematita tabular e granular das pilhas mostrou correlação direta com o IM. Sabe-se que alta participação de minerais porosos

* Contribuição técnica ao 44 Seminário de Redução de Minério de Ferro e Matérias-primas, $15^{\circ}$ Simpósio Brasileiro de Minério de Ferro e $2^{\circ}$ Simpósio Brasileiro de Aglomeração de Minério de Ferro, 15 a 18 de setembro de 2014, Belo Horizonte, MG, Brasil. 
impacta no processo de pelotização. Os testes com pilha referência mostraram que a granulometria e superfície especifica possuem relação direta com a densidade e produção. Enquanto que a correlação com a pilha dura devido à indisponibilidade do PSI no período do teste.

Testes com pilha macia mostraram que a granulometria e superfície especifica possuem relação direta com a densidade, pressão e produção.

\section{Agradecimentos}

Agradeço a todos que colaboraram direta e indiretamente neste trabalho. Agradeço a todos da equipe de Operação e Unidade Técnica das Usinas V a VII, Laboratórios Químico, Físico e de Caracterização de Materiais da Diretoria de Pelotização da Vale/Tubarão.

Em especial gostaria de agradecer a todos da Usina Piloto/DIPE/Vale Tubarão que empenharam e dedicaram no trabalho.

\section{REFERÊNCIAS}

1 Ribeiro MR. Investigação das características dos minérios de ferro da CVRD que influenciam seu comportamento na moagem. 70p. Dissertação de Mestrado. REDEMAT, UFOP, CETEC, UEMG, Ouro Preto; 2004.

2 Schneider CL, Neumann R. Considerações sobre a geração de superfície específica em minérios de ferro porosos. XIX Encontro de Tratamento de Minérios e Metalurgia Extrativa. ; 2002; Recife; Brazil.

3 Mourão JM, Stegmiller L. Influência da estrutura dos minérios de ferro na sua moabilidade. In: Encontro Nacional de Tratamento de Minérios e Hidrometalurgia, 14. Salvador; Brazil. Anais. São Paulo: Associação Brasileira de Metais, 1990. v.1, p. 221 243.

* Contribuição técnica ao $44^{\circ}$ Seminário de Redução de Minério de Ferro e Matérias-primas, 15은 Simpósio Brasileiro de Minério de Ferro e $2^{\circ}$ Simpósio Brasileiro de Aglomeração de Minério de Ferro, 15 a 18 de setembro de 2014, Belo Horizonte, MG, Brasil. 